\title{
Internationalizing a Master Curriculum: Students' Perspectives on Online Education
}

\author{
Sonia M. Gómez Puente \\ Eindhoven University of Technology (TU/e), the Netherlands
}

\begin{abstract}
The internationalization of the curriculum is nowadays an important part of the educational strategy of higher education institutions. Universities worldwide foster mobility of teaching staff and students and provide exchange programs as core elements of their internationalization policy. Transforming study programs towards an international curriculum has become a priority also for the Eindhoven University of Technology (TU/e), the Netherlands. An experiment was conducted to re-design the master elective course Design for Behavioral Change of the Industrial Design study program at the TU/e. The purpose of the experiment was to study the suitability of the e-learning methods employed in the re-design of this master course that may foster internationalization. In particular, the study focused on investigating students' and teachers' perceptions in order to learn whether elearning platforms can be implemented faculty-wide to facilitate students' access to distance education while attending courses in universities abroad. Study patterns of a limited number of students enrolled in the online part of the master course Design for Behavioral Change were investigated. Research questions related to the support of the online platforms, the motivation to attend a course at distance, and the quality of the course and the materials were the interest of this study. Results showed that the difference in time regarding the online lectures, the digital assessment system used and the e-learning resources influenced students' lack of motivation to complete the course. Despite the results, the quality of education of this online course was considered to be optimal. Considerations for further research include study the impact of online education on the self-directed learning of students.
\end{abstract}

\section{Introduction}

The increase of economical exchange worldwide together with the influence of the globalization movement and the growth of the knowledge society put forward another dimension of higher education. Demands to educate students to higher standards to respond to the economic, societal, health and environmental challenges and alike changed the structure existing till now [1]. The new status quo of the globalizing structure was characterized by the use of English as the language of communication in business, economic and scientific exchange [1]. Also, the upswing of the international exchange influenced the boost of the integration of technology and information technology (IT) in every single activity [2]. The expansion of the globalization, together with the upturn of the knowledge society played a major role in intensifying research, internationalizing education, and nurturing innovations in all sectors.

\section{Trends and Perspectives on Internationalization}

Fostering internationalization of education is a major drive for most of the European universities and overseas. The rationale behind internationalization is to promote academic mobility and encourage students' exchange programs in order to attain competitiveness and achieve economic and knowledge advantage in this global world [1]. In this context, internationalization and globalization are connected to the idea of bringing about a new type of society responding to the challenges of the current economic and technological developments. Although both concepts are interconnected these are however different in nature and oftentimes are erroneously used with the same or similar meaning [2]. Within the notion of internationalization several perspectives for the organization of internationalization in higher education can be understood. Some experts define internationalization as the involvement of partner organizations start up programs by which mobility for students, teachers and researchers is stimulated. Within this notion the development of double degree programs, the initialization of research projects, the organization of language courses and inter- or crosscultural activities are included [2]. Furthermore, internationalization get oftentimes a broader dimension than globalization. Globalization implies the boost of technology and the use of it within education in general, and more specifically, within higher education. From the point of view that exchange of knowledge within a knowledge society where people, values and ideas go beyond borders, globalization can have some impact on how 
internationalization in higher education takes place in a country or community [2].

Enhancing the curriculum of the international classroom includes foreign language programs, cultural awareness, providing cross-cultural and skills development activities. Some universities go beyond in their internationalization approach by formulating policies and by integrating learning outcomes in the study programs and at course level [2].

In addition, flexibilization of education is a key element to enable internationalization and exchange of knowledge, and can create an impact in the increase in the number of students attending programs across borders [2]. Flexibilization can boost also exchange and internships programs promoting an easy mobility of the international classroom community [3]. However, students interested in participating in exchange or internship programs abroad may fail to do so when the university does not offer online courses that can be easily accessible when study in a foreign country.

\subsection{Building Bridges: A New Era of Cooperation among Universities}

Interesting in the current developments in the international arena is the strategic partnership among universities by which complementary strengths are combined to jointly achieve broader initiatives that can create an impact to the society frequently in cooperation with the industry. International cooperation and alliances is marking a new era in internationalization of education. In Europe, as an instance, there are several initiatives taking place in order to share European values and foster an identity by building bridges towards quality-oriented programs and competitiveness of European higher education [3]. Some already working initiatives aim at piloting activities and testing different cooperation models among European universities, for instance, within the framework of Erasmus+ program and alike. The main goals of these alliances are to build sustainable and long-term partnerships in all kind of fields across Europe where students can attend courses from a variety of joint student-centered curricula delivered across inter-university campuses [4]. In addition, by attending these programs other types of knowledge and skills can be developed as students will be part of interdisciplinary teams addressing challenged-based projects to meet the societal problems in constant change. With these initiatives the ambition of European countries is to construct a European Education Area [5] able to share values and carry out projects that envision a new era of tactical associations and agreements to facility knowledge sharing and transfer of people to foster research and education [5].

Some examples of these strategic alliances are the newly-started Eurotech Universities Alliance that incorporates six European universities in the field of science and technology. This alliance is exposed by the cooperation in research and education where possibilities to conduct collaborative projects and prepare joint project proposals with the partner universities are some of the activities in the field of research and scientific development. In terms of education, the Eurotech Alliance has the objective to become a leading European ecosystem for education in Science and Technology [3]. The ambition is to design and organize study programs together in different fields in order to meet the challenges and demands of the society. The aim is to combine knowledge in these scientific fields with a clear emphasis on entrepreneurship and innovation, health and bioengineering, sustainable society, additive manufacturing, and Artificial Intelligence for engineering systems [3].

The need to internationalize the curriculum and facilitate distance education through online methods and platforms has become therefore a crucial priority in higher education.

\section{Theoretical Considerations}

Internationalization is deeply linked to the notion of flexibilization of education. Flexibilization of education is essential when learning becomes the vehicle to support instruction in an international curriculum. However, flexibilization of education has several perspectives and meanings depending on the ambition of the higher education institution, the educational strategy or policy, but also the field and context in which this term is used. The most common definition of flexibilization in relation to the provision of education is the support of the delivery of education regardless pace, time, place, content, and level [4]. As the future of European and worldwide universities is to build bridges and facilitate mobility and jointly organized study programs, flexibilization becomes the platform to boost this vision and ambition of international cooperation. In this context, flexibilization provides opportunities to make learning paths accessible for students. In order to enhance independent and critical learners able to make own decisions, the selection of course choices allows students to take control of their learning process. Individual students can draw own educational path and select a number of courses to complete an individualized dossier or 'playlist' and follow own pathway within own institution but also overseas. Each university determines the framework of the flexibilization and also the partners with whom to offer joint programs enhancing the quality of their education and degrees [6].

A good example of the flexibilization of education in the Netherlands is the Acceleration Plan for Educational Innovation with ICT. This is a four-year project of The Netherlands Association of Universities of Applied Sciences, and The Association of 
Universities in The Netherlands (SURF). One of the goals of the SURF initiative is to foster a rapidly and reliably use of the opportunities available for higher education so that universities can become more flexible to allow personal tailoring of education for students [7].

Fostering the design of individualized learning paths is extremely relevant to build the capacity of the new type of future employees. Flexibilization of education in this regard is framed in the nurturing of the capacity to have a more control and responsibility to the students towards a lifelong learning approach of own development.

For the purpose of this study and building upon the variety of perceptions on flexibilization, we adapt the term 'flexibilization' to the context of this study in the meaning of provision of online, distance and e-learning education. We define online distance learning as the access to learning experiences via the use of some technology [8, pp. 130] and a link with notions such as connectivity, flexibilization, and the possibility to include interactions. In online learning, students can still be in a classroom with a teacher while they work in platforms on assignments and projects [8]. Online learning is sometimes combined with blended-learning when additional teaching in classroom is combined. Distance learning is described by many authors [9] as the method that relies on digital platforms of communication, e.g., video calls, discussion boards, and learning management systems (LMS) in environments in teacher absence and interaction between teachers and students is included, by which the principles of learning autonomy and active involvement are crucial elements. Similarly, elearning is commonly defined as the method strictly being accessible using technological tools that are either web-based, web-distributed, or web-capable [8, pp. 130]

Numerous experts have investigated the relation between distance and online learning with students' behavior and, more specifically, in relation to selfdirected learning [10]. Research studies reflect on experiments on efficient online learning and the core elements of the use of technology in education. These studies point out that success and school achievement in distance education lies extensively in the capacity of the learners to organize and manage own learning process [11].

Current developments in the use of technology in education enable learners to have access to course content regardless time and space as well as to promote individualized but also self-independent learning. The advantages of online learning are found in the supportive capacity that technology and Web-oriented platforms bring in to foster communication and collaboration [11], but also to bring together communities in collaborative environments. Rovai [12] reports on successful interventions in online communities when students carry out tasks together perceiving a feeling of trust and interaction. Also, the use of web channels can facilitate the giving and receiving of feedback, discussions, visualization of analytics to re-adjust the learning process or to improve the quality of materials [12].

Multiple studies present the benefits of online platforms with emerging technologies that support interaction and the teaching and learning [12]. These studies report positively about the engagement of students who otherwise may not be able to enroll in a traditional classroom course [13]. Research on elearning educational platforms also reports about the success of students' engagement in addition to the motivation and teachers' satisfaction with the use of technology in the classroom [13].

Despite the fact that there are advantages when using online learning to facilitate the learning process for students who need to work on their own schedule and at their own pace when attending courses abroad, there are, however, some drawbacks as well. Online teaching and learning request from students selfdirected learning skills to manage own learning, and responsibility for own educational development [14].

The decrease in direct guidance in the case of distance education emphasizes the importance of students' adaptation to learning strategies. In these contexts abroad with teachers' absence it becomes difficult to apply the self-regulated skills such us organization, self-management of time and work, goal orientation, discipline for preparation of exams and assignments, and even more importantly, motivation [14].

The educational theories and didactical principles that underly constructivism, meaningful and deep learning, are considered a significant component as well in the design of online education. In meaningful learning students experience and learn from applying knowledge in an active manner. Fundamental principles of distance education underlie the need to include educational principles in the design of online learning education to encourage self-directed learning and autonomy, as well as active involvement. These are essential elements for successful design of online learning [15].

The application of educational strategies for the support of self-regulated learning in distance education indicates the importance of feedback for the monitoring and adaptation of learner's cognitive processes through a continuous cyclic and repetitive process.

Coaching and feedback are essential to scaffold students' learning. It also supports the development of students towards self-directed learning [15]. Hattie and Timpeley [17] argue that effective feedback to create change occurs when questions are used that guide students in the notions of feed up, feedback, and feed forward. However, the level of success depends as well on whether the feedback is given at the level of the task, the process of understanding on how to carry out the 
task, the metacognitive process, or to the self or personal level. Another important premise of effective feedback according to Hattie and Timpeley [17] is that it should have a clear goal or purpose, with a meaning and it should be given in a clear manner in order to help the student make connections between the prior knowledge and the task ahead. In order to gain effective feedback at the task, process, and selfregulatory levels interrelation among these elements is more powerful when it is inserted in the design of online education.

The literature also collects experiences in which feedback is given by teachers, peers of himself. These examples from the literature include educational strategies that facilitate the monitoring, effort, time and environmental management and self-efficacy [16]. This together with other educational principles for the design of online learning environments (e.g. having students to work on tasks in authentic scenarios, providing feedback, etc.) aim to maximize the engagement of the student with the activity, enable the communication and maximize opportunities for feedback and reflection [18].

\section{Instructional Design: Adjusting the Master Course Design for Behavioral Change to Facilitate Online Learning}

Design for Behavioral Change is a master elective course within the master curriculum of the Industrial Design (ID) department [17]. The course aims at having students to gain knowledge and skills pertaining to the design of technologies that can help people change behaviour and attitude without coercion, manipulation or deceit. The orientation of the course is geared towards informing about and having students to apply the design of interactive technologies with theories deriving from the fields of health and social psychology, communication and behavioural economics. The educational forms of the course have been of traditional character consisting of lectures to familiarize students with theories, self-study assignments to apply the insights of the theories gained and the application of these theories to design through hands on workshops and a design case. However, with the internationalization of the curriculum and the objective to facilitate students attending an exchange program in a university overseas while having access to the ID master program, a new dimension for learning was employed in this master course.

\subsection{From Traditional to Online and Blended- Learning}

The master elective course Design for Behavioral Change at the Industrial Design department was adjusted to include an online set-up to allow students to attend the course from universities overseas. The course consisted of an 8-week program including lectures, workshops, self-study, individual and challenge-based group assignments. Although the structure remained similar to the course offered oncampus, some blended-learning and e-learning elements were introduced. The traditional face-to-face version of the lectures and assignments were still provided for the students attending the course in the Netherlands. However, and in order to enable students to attend online lectures and be assessed at distance, the model TPACK model [18] was followed. The TPACK models provides a suitable framework for teachers to integrate technology in their teaching and learning, and have them think of the content in terms of knowledge and skills while applying the didactics appropriate for their education [19].

Having in mind the content to learn, the teaching staff initiated the changes in the course by transferring the classroom learning environment and the students' assignments from a physical environment to a digital one.

To facilitate online education, the course included life streaming lectures. Streaming lectures were provided so that students, mainly in Asian countries enrolled in an exchange program, could attend the lectures at Dutch time.

In addition, the live streaming platform incorporated channels to interact with students located abroad. The platform included possibilities to ask questions as well. The aim was to create interaction and stimulate active participation in the classroom during these lectures. Lectures were live streamed and students both in-class and in universities in other countries attended the lessons at the same time. Time difference between the Netherlands, China and Japan is seven and eight hours respectively. Assignments and course content was posted weekly basis in the Learning Management System (Canvas) of the university.

Besides the lectures, the courses also included projects and exercises in small teams. These team activities were carried out by groups of two students outside the classroom. For students living abroad they needed to incorporate an online platform to facilitate the communication and discuss group project activities. Often Skype or similar web-based technologies and channels were used. For both students abroad and nationals, the assignments were the same and no major changes in the form or objectives of the activities took place.

The assessment of the course Design for Behavioral Change consisted of a combination of both individual as well as groups assignments. The group assessment included the application of the behaviour change theories to the design and evaluation of systems in teams; the use of the frameworks of mechanisms and principles for exploiting influence in design, etc. What it become a particular challenge was the individual assessment. It consisted of a mid-term multiple choice exam to test the understanding of the core behaviour 
change and persuasion theories. For the organization of the mid-term exam an online platform was employed allowing for assessing students regardless time and location. The digital assessment was employed for both students on-campus and students living abroad.

The interim assessment consisting of a multiplechoice online test on the Cirrus platform which was uploaded in the ProctorU system [20]. Cirrus is a testing software and with Proctorio as online proctoring software. Online proctoring allows students to take part in a test, in this case in Cirrus, and this can be done both on or off campus. Students conduct the online assessment in their own computer or laptop in a secure manner within an allotted time slot. In this kind of online assessment methods, the Proctorio's online proctoring software was used as platform in which the Cirrus testing software browser was opened providing Proctorio, therefore, a secure environment to conduct examinations. The ProctorU system was only employed with students living abroad.

The online test was planned to take place at the same time as the test was administered in the Netherlands.

\section{Research Questions and Method}

The overall purpose of this study was to experiment with e-learning platforms in order to consider scalability of online education and offer more ecourses for exchange students. This to learn from the results and evaluate whether these platforms would be options to internationalize the curriculum as part of the departmental policy. In light to understand the impact of online and distance education in the master elective course Design for Behavioral Change we formulated the following research questions for this experiment: (1) Is life streaming a suitable lecture format for students registered in an exchange or internship program abroad? (2) Is ProctorU an adequate online system to assess students abroad? (3) Are students enrolled in an exchange program abroad satisfied with this online version of the course?

The methodology used to conduct this investigation was based on a triangle approach combining qualitative research methods. The Table 1 below indicates the methodology for this research.

Table 1. Research methods

\begin{tabular}{|l|l|l|}
\hline Method & Research approach & $\mathbf{N}=$ \\
\hline Qualitative & $\begin{array}{l}\text { Students' survey } \\
\text { Likert scale 1 to 5 }\end{array}$ & 4 \\
\hline & Individual meetings & 4 \\
\hline & Teacher's interviews & 1 \\
\hline
\end{tabular}

The total number of students registered in this course was $\mathrm{N}=43$. However, only $\mathrm{N}=4$ students were enrolled in an exchange program and attended this course online from universities abroad. To study the benefits of this pilot experiment we followed $\mathrm{N}=4$ students' patterns which were collected through individual interviews. In addition, we also collected in students' survey students' satisfaction regarding the feasibility of this online course. For the survey we used Likert scale questionnaires with a 1 to 5 scale being 1 totally disagree and 5 totally agree. Teacher's satisfaction was also collected in an interview.

\section{Results}

We considered three main questions for this study. Regarding the suitability of the live streaming as a format for the provision of lectures for students abroad, we observe students' high satisfaction about it (4.0) (see Figure 1, Students' course evaluation). In general, we appreciate in a moderate manner (3.0) that students did not encountered major problems to attend the course at distance. With respect to whether students could understand the theory and participate in the course projects, students are moderately (3.0); while students' are highly satisfied with the course as it helped students implement interest in career development (4.0). Similar high satisfaction (4.3) was found in that despite that students were living abroad, it did not prevent them to work on project activities with students participating in the course on-campus in the Netherlands.

With regards to the second research question of this study about the suitability of the digital assessment system to assess knowledge at distance, we observe a considerable level of dissatisfaction (2.0) concerning the system.

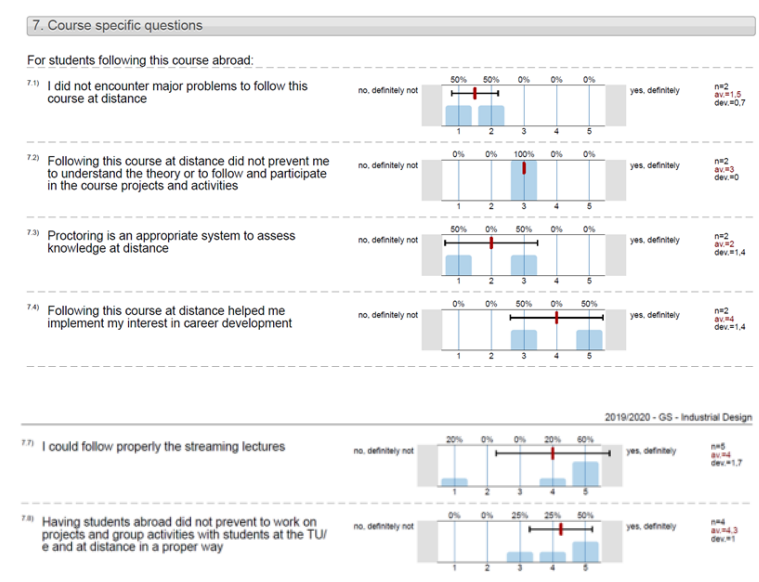

Figure 1. Students' course evaluation

Individual interviews were conducted with the students participating in this course overseas in order to capture their impressions about the suitability of this online course offered to facilitate exchange programs.

We summarize the feedback from students with a review of the statements and impressions on online education. Students described the drawbacks as 
'Difficult to synchronize 'streaming lectures' with differences in time (the Netherlands and Asian countries); 'Difficult to synchronize 'group work that caused lack of motivation'. With regards to the online assessment, students mentioned that 'it was difficult to adjust to exam time'; 'Intrusive program'; 'First time needs practice'. Despite the description of the difficulties in this pilot course students considered that 'There was no impact on quality of education: feedback, assignments'. Students' perceptions on technology in education were positive and did not influence students' attitudes towards e-learning.

Regarding the teacher's perception, the teacher mentioned to be positive on the experience with this online course due to a number of reasons. First of all, the introduction of technology in education, i.e., live streaming, was easy to use. However, additional technical and organizational support for the teachers remain a crucial point for success. Secondly, and regarding the digital assessment, i.e., remote proctored exam, the teaching staff described this system as very intrusive as privacy is, to some extent, transgressed.

The results of this study indicate that there are factors such as time difference between the Netherlands and Asian countries, e.g., China and Japan, that influence the motivation of the students to attend the online lectures. Similarly, group assignments were difficult to carry out from different locations. Likewise, the online assessment system seems to be a downside form of assessment.

\section{Conclusions and Implications for Improvement and Future Research}

In the theoretical considerations in this study we considered a number of educational principles to integrate when designing online courses. First of all, feedback is a powerful tool to guide students. Feedback can also be of more value depending on when it is employed to adjust behavior, task of the self. In this experiment, feedback on content and assignments was given while self-direction was expected from the students, as Industrial Design is a study program which strongly lies in educational principles such as learning students to become self-directed learners in the choices, they make to select courses, in competency development and in the development of an identity and vision as designers. Furthermore, this experiment was conducted in a master course and students are supposed to have learned and developed self-directness throughout the bachelor program. Therefore, the fact that this experience has not been fully positive in terms of motivation for students, it can be understood perhaps due to a number of reasons. Time difference between Asian countries and the Netherlands made the attendance to the lectures a difficult undertaking to follow in real time. When students on-campus had morning or afternoon lectures, students abroad had evening sessions. Also, the group project assignments needed to be carried out in teams oftentimes from students in different countries. This made it difficult sometimes to engage them in active participation in the teamwork. Moreover, the digital assessment software program was difficult to implement due to the that not only time difference was not convenient but also because the privacy concerns about the system. Furthermore, this digital system employed in this course was the first time applied to assess students online in the whole university. Therefore, the use of this tool had a logical reaction and a natural sense of resistance towards the unknown.

The analysis of this experiment cannot only be done from the perspective of guidance in self-directness or from the technology perspective. The design of education in the context of online and distance education needs to be addressed as well. Despite the efforts paid by the teaching staff to re-design the course to meet online demands of distance students, it is still a need to work on the adjustments of the assignments in order to make them more tailor-made to the students.

An iteration in the integration of the TPACK model can be considered in the re-design of education. This model offers an excellent framework for the design of online education and the introduction of technology in education. Tailor-made assignments to meet individual needs aligned with the content, the technology and the didactics behind need to be addressed.

Considerations point out that introducing innovations in education is not a question of just changing assignments. The didactical and technical support is crucial to boost a sustainable transformation towards the flexibilization and internationalization of the curriculum. Reflexion, experimentation and iterations in the design of education should be part of all educational reforms both at program as well as at course level.

It is worth mentioning that the process of internationalizing education is not a one-day action. Transforming current educational paradigms asks also for a change in the 'mindset' of the teaching staff to make use of technology of education with appropriate insights and understanding in didactical approaches and methods. Special emphasis should lie in stimulating self-directed learners and supporting meaningful choices in courses and decisions that help guide own learning path.

Finally, there are interesting lessons learned to draw from this study. This experience provide numerous venues and implications for further research. The study of the impact of re-design of the course Design for Behavioral Change and the adjustments of the assignments to meet the needs of the distance students in an online environment can bring about interesting insights for the educational practitioners. In addition, the effectiveness of the online education and the impact on motivation and self-directed learning attitudes of the students will be considered in future research. The latter is specially of great importance as there is a need 
to contribute with new insights to the body of knowledge in this field so that the teaching community and the universities as a whole can benefit from the results of this study to transform education towards the internationalization and flexibilization of the curriculum.

\section{References}

[1] P.G. Altbach, and J. Knight, "The Internationalization of Higher Education: Motivations and Realities", Journal of Studies in International Education, (2007), 11, 3-4, https://doi.org/10.1177/1028315307303542.

[2] J., Mittelmeier, B., Rienties, A., Gunter, and P. Raghuram, Conceptualizing Internationalization at a Distance: A "Third Category" of University Internationalization. Journal of Studies in International Education, (2020), 1-17 (C) European Association for International Education. https://doi.org/10.1177/1028315320 906176.

[3] J. Drennan, J. Kennedy, and A. Pisarski, "Factors Affecting Student Attitudes Toward flexible Online Learning in Management Education", The Journal of Educational Research, (2005), 98(6), pp-331-338. https://doi.org/10.3200/JOER.98.6.331-338.

[4] EuroTech. (2020). 10 Years empowering society. https://eurotech-universities.eu/.@ EuroTech Universities/ 2020. Access date: November $5^{\text {th }}, 2020$.

[5] European Commission. (2020/09/07) 24 new European Universities reinforce the European Education Area (2020/09/07).https://ec.europa.eu/commission/presscorner/d etail/en/ip_20_1264. (C) European Commission. IP/20/1264. Access date: October $29^{\text {th }}, 2020$.

[6] O. Simpson. Supporting students for success in online and distance education. Routledge, (2014), ISBN: 978-0415-50910-7.

[7] Surf. SURF is the collaborative organization for ICT in Dutch education and research. https://www.surf.nl/en. Access date: November $20^{\text {th }}, 2020$.

[8] J.L. Moore, C. Dickson-Deane, and K. Galyen, "eLearning, online learning, and distance learning environments: Are they the same?", The Internet and Higher Education. ELSEVIER. (2011), 14, 2, pp- 129-135.

[9] E, Nikolaki, M., Koutsouba, G. Lykesas, and F. Venetsanou, "The Support and Promotion of Self - Regulated Learning in Distance Education", European Journal of Open, Distance and E-Learning. (2017).

[10] R. Garrison, "Implications of Online Learning for the Conceptual Development and Practice of Distance Education", Journal of Distance Education, (2009), 23, 2, 93-104.
[11] T. Anderson, D. Annand, and N. Wark, The search for learning community in learner paced distance education: Or, "having your cake and eating it too!". Australian Journal of Educational Technology, (2005), 21(2), 222-241.

[12] A.P. Rovai, (2002) "Sense of community, perceived cognitive learning, and persistence in asynchronous learning networks", Internet and Higher Education, 5, pp- 319-332.

[13] L. Chmiliar, "Self-Regulation skills and the postsecondary distance learner", Procedia - Social and Behavioral Sciences, (2011), 29, pp-318-32.

[14] D.U. Bolliger, and O. Wasilik, "Factors influencing faculty satisfaction with online teaching and learning in higher education", Distance Education, (2009), 30 (1), pp 103-116 https://doi.org/10.1080/01587910902845949.

[15] H. Coates, "A model of online and general campusbased student engagement", Assessment and Evaluation in Higher Education, (2007), 32(2), pp 121-141 https://doi.org/10.1080/02602930600801878.

[16] C.C. Robinson, and H. Hullinger, "New Benchmarks in Higher Education: Student Engagement in Online Learning", Journal of Education for Business, (2008), 84(2), pp-101109 https://doi.org/10.3200/JOEB.84.2.101-109.

[17] J. Hattie, and H. Timperley, "The Power of Feedback" Review of Educational Research, (2007), 77, 1, pp- 81-112 DOI: $10.3102 / 003465430298487$.

[18] S.M. Gómez Puente, "Designing E-learning Education To Promote Internationalization: Lessons Learned from an Online Master Course“, (2020), Proceedings (online) The Ireland International Conference on Education (IICE 2020), Dún Laoghaire, Ireland, https://www.iicedu.org/.

[19] Mishra P., and Koehler, M.J., "Technological pedagogical content knowledge: A framework for integrating technology in teacher knowledge". In Teachers College Record, (2006), 108(6), pp. 1017-1054. Available online http://mkoehler.educ.msu.edu/OtherPages/Koehler_Pubs/T ECH_BY_DESIGN/TCRecord/mishra_koehler_tcr2006.pdf

[20] Proctoru, Exam Security. Done Right. () 20082021 ProctorU Inc. A Meazure Learning Company. https://www.proctoru.com, Access date: 6 April 2020.

\section{Acknowledgements}

I would like to thank you very much prof. dr. Panos Markopoulos, responsible teacher of the course Design for Behavioral Change, for his effort and input in developing and integrating technology in this online master course. I am also very thankful to the master students who participated in this study for the valuable feedback they provided to adjust this online course. 